\title{
ZUSES
}

science for a changing world

Prepared in cooperation with the

National Oceanic and Atmospheric Administration

\section{Sun-illuminated sea floor topography of Quadrangle 13 in the Stellwagen Bank National Marine Sanctuary off Boston, Massachusetts}

By Page C. Valentine, Jessica L. Baker, and Tanya S. Unger

Geologic Investigations Series Map I-2713

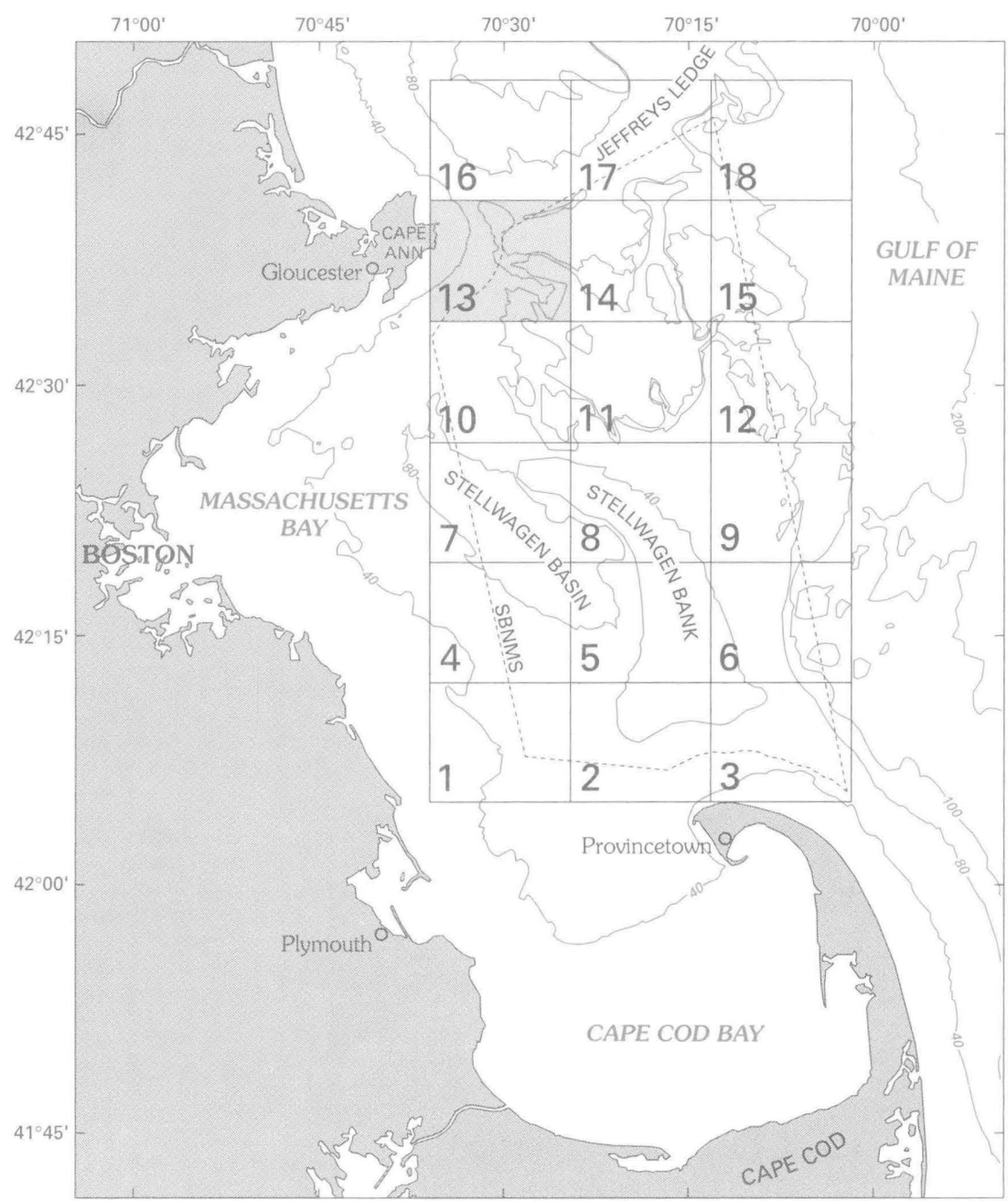

